\title{
Epistemological Beliefs and Academic Achievement
}

\author{
Halis Adnan Arslantaş \\ Correspondence: Halis Adnan Arslantaş, Faculty of Education, Eskişehir Osmangazi University, Eskişehir, Turkey
}

Received: September 21, 2015 Accepted: October 13, $2015 \quad$ Online Published: October 20, 2015

doi:10.11114/jets.v4i1.1107

URL: http://dx.doi.org/10.11114/jets.v4i1.1107

\begin{abstract}
This study aimed to identify the relationship between teacher candidates' epistemological beliefs and academic achievement. The participants of the study were 353 teacher candidates studying their fourth year at the Education Faculty. The Epistemological Belief Scale was used which adapted to Turkish through reliability and validity work by Deryakulu and Büyüköztürk (2005) and consisted of three sub-dimensions (i.e. belief of learning depending on effort, belief of learning depending on talent and belief of the existence of only one truth). In data analysis, $t$-test, one-way ANOVA and Pearson Product-Moment Correlation Analysis were employed. The findings showed that the teacher candidates' epistemological beliefs differed based on major. In addition, it was found that there was a statistically significant relationship between only the belief of learning depending on talent, among other sub-dimensions of epistemological beliefs, and academic achievement.
\end{abstract}

Keywords: epistemological beliefs, academic achievement, socio-economic variables

\section{Introduction}

Beliefs are strong determiners of individuals' thoughts and behaviours. For this reason, educators should consider many type of beliefs such as self-efficacy belief, belief toward intelligence and belief toward learning in terms of learning and teaching (Deryakulu, 2006, cited in İlhan \& Çetin 2013). This necessity also includes epistemological beliefs that are shown to be important in the learning-teaching process.

The examination of epistemological beliefs as a branch of philosophy in education and psychology started with Piaget's work on genetic epistemology in 1950's and the studies of Perry, who was an educational psychologist, with university students in 1960's. Piaget attracted the attention to this field in which philosophy and psychology are intersected by presenting his cognitive development theory that he defined with the concept of genetic epistemology (Hofer \& Pintrich, 1997; Schommer-Aikins, 2004 cited in Bedel \& Çakır).

Perry, who conducted the first studies in this issue, described epistemological beliefs as those reflecting individuals perspectives on the criteria in defining knowledge, its limitations, precision and how it is acquired. As Brownlee (2003) reported from Perry (1981), he defined four different characteristics related to epistemological beliefs that teacher candidates have during their education including dualism, multiplism, relativism and commitment (Brownlee,(2001) cited in Belet \& Güven, 2011). In short, Perry defined epistemological beliefs as "individuals' perspectives on what knowledge is, how it is acquired, its certainty, limitations and criteria" (Brownlee, Purdie \& Boluton-Lewis, 2001 cited in Arslan et al.). Perry's studies on epistemological development with male university students formed the basis for much further research in this issue.

Another milestone in the examination of epistemological beliefs is the studies by Schommer and her colleagues that presented a theoretical framework for many studies later on (Schommer, 1990, 1993, 1997; Schommer \& Walker, 1995 cited in Bedel and Çakır). Schommer tried to explain epistemological belief with a model of four dimensions including "simplicity of knowledge", "certainty of knowledge", "quick learning" and "learning being an innate ability" (Schommer, 1990 cited in Deryakulu, 2004) and defined epistemological beliefs as individuals' subjective beliefs of the definition of knowledge and the way in which the process of acquiring knowledge takes place (Schommer, 1990 cited in Deryakulu \& Büyüköztürk, 2002).

Another classification similar to the levels proposed by Perry (1970) related to epistemological beliefs was made by Baxter Magolda (1992). Baxter Magolda conducted a five-year longitudinal study with 101 university students including 51 female and 50 male. In that study, interviews consisting of short-answer and open-ended questions reflecting students' epistemological beliefs every year were performed. As a result of the study, epistemological beliefs 
were explained in four dimensions that were absolute, transitional, and independent and commitment. Those who believe in the certainty of knowledge have an understanding that all knowledge is certain, experts know all the rights, and individuals' duty is memorizing what is delivered by the experts. Those who believe in transition of knowledge start to understand that experts do not not everything, and knowledge might not be certain and absolute. Those who believe in the independence of knowledge have an understanding that most knowledge consists of contents that are uncertain and experts are not the only source of knowledge. As for those who believe in contextual knowledge, they think that some knowledge can be more valuable than the rest depending on the content although having the understanding that certainty is not in the nature of knowledge (Illhan et al., 2013).

Individuals who have developed epistemological beliefs mostly believe in the complexity of knowledge, the changeability of knowledge, learning taking place not suddenly but in time, and ability not being innate but could be developed later (Deryakulu, 2004). The reason is that epistemological beliefs create an epidemic suspicion in students. These beliefs can change them through social interactions and reflective thinking (Bendixen, 2002 cited in Arslan et al.).

Epistemological beliefs and students' learning strategies they use in processing knowledge are two factors that reciprocally affect each other. While individuals' epistemological beliefs affect their strategies of studying, the learning strategies they use in processing knowledge affects their formation of epistemological beliefs. Deryakulu (2004), Schommer (1993), Schommer, Crouse and Rhodes; Önen (2011), Rodriguez and Cano (2006), Cano and Cardelle-Elawar (2004), Buelens, Clement and Clarebout (2002), Ravinran, Greene and Debacker (2005), Debacker and Crowson (2006), Phan (2006), Phan (2008), Philips (2001), Chan (2003), and Kızılgüneş, Tekkaya and Sungur (2009) examined the effect of epistemological beliefs on learning strategies, academic achievement and level of understanding mathematical texts (Arslan et al.).

However, there were also those arguing that epistemological beliefs should only involve beliefs related to knowledge, and beliefs of learning should not be included (Clarebout et al., 2001 cited in Belet \& Güven 2011). Examining the studies in the literature, there seems to be an agreement on the concepts of cognition and metacognition being different, and can be distinguished, from each other. Accordingly, while cognitive skills are required in fulfilling a task, metacognitive skills play a role in understanding how that task is fulfilled. Metacognitive skills are better determiners of learning compared to intelligence. In general, intelligence explains nearly $10 \%$ of the variation in learning while metacognition explains $17 \%$. When taken together, these two variables explain $20 \%$ of the variation in learning. These findings show that the cognitive limitations that hinder students' learning process can be compensated by metacognitive awareness (Veenman, van Hout-Wolters \& Afflerbach, 2006 cited in Bedel \& Çakır; Schraw, 1998 cited in Bedel \& Çakır).

\section{Method}

In this section, information regarding study design, participants, data gathering tool and statistical techniques used in data analysis is presented. This study employed correlational survey model. Correlational survey model aims to reveal whether two or more variables change together, and the degree of this change (Karasar, N. 2005).

This study revealed the relationship between teacher candidates' epistemological beliefs and the learning strategies they used, and whether these learning strategies, belief of learning depending on effort, belief of learning depending on talent and belief of the existence of only one truth differed based on gender and major.

The participants of the study were fourth year teacher candidates at the Elementary Education Department of Ataturk University Education Faculty. A total of 353 teacher candidates constituted the sample; $23.8 \%(\mathrm{n}=84)$ studied elementary teaching (E.T.), 25.2\% $(n=89)$ elementary mathematics teaching (E.M.T.), 19.3\% $(n=68)$ science teaching (S.T.), $16.4 \%(\mathrm{n}=58)$ social studies teaching (S.S.T.) and $15.3 \%(\mathrm{n}=54)$ preschool teaching (P.T.). Besides, $45.6 \%$ of the participants were male and $54.4 \%$ female.

The Epistemological Belief Scale developed by Schommer (1993) was adapted to Turkish through validity and reliability work by Deryakulu and Büyüköztürk (2005). Including three sub-dimensions being "belief of learning depending on effort", "belief of learning depending on talent" and "belief of the existence of only one truth", the scale consisted of 34 items in 5-point Likert format with the options of (1) strongly disagree, (2) disagree, (3) not sure, (4) agree and (5) strongly agree. A high score from each of the sub-dimensions in the scale refers to immature beliefs related to that sub-dimension while a low score to mature beliefs. The Cronbach Alpha internal reliability coefficient of the scale was between .64 and .84. The Cronbach Alpha internal reliability coefficient re-calculated for the current study was found to be between .65 and .84 .

The data in the study were gathered by administering the Epistemological Beliefs Scale to the participant teacher candidates in the spring semester of 2010-2011 academic year. The average answering time for the scale was observed 
to be around 8-10 minutes. The analysis of the obtained data included three steps. The details regarding these steps are presented below:

(i) Step 1 Before moving on to the statistical analyses, the data gathering tool administered to the teacher candidates was scored based on the 5-point Likert format.

(ii) Step 2: To determine whether the teacher candidates' epistemological beliefs differ based on the gender variable, independent samples t-test was employed, and based on major one-way ANOVA was used.

(iii) Step 3: To identify the relationship between the teacher candidates' scores in the epistemological beliefs scale and their cumulative grade point average, Pearson Product-Moment Correlation Analysis was used.

\section{Results}

According to the t-test results based on the gender variable, no significant differences were revealed for the teacher candidates' scores in Epistemological Beliefs Scale, including each of the three factors. It was found that the teacher candidates being male or female did not cause any difference in their belief of learning depending on effort (Factor 1), belief of learning depending on talent (Factor 2) and belief of the existence of only one truth (Factor 3) (see Table 1).

Table 1. Independent Samples T-Test Results of Teacher Candidates' Scores of Epistemological Beliefs Based on Gender Variable

\begin{tabular}{|c|c|c|c|c|c|c|}
\hline Variable & Gender & $\mathrm{n}$ & $X$ & $\mathrm{sd}$ & $\mathrm{t}$ & $\mathrm{p}$ \\
\hline \multirow{2}{*}{ Factor 1} & Male & 161 & 35,3478 & 9,91291 & \multirow{2}{*}{.606} & \multirow{2}{*}{.545} \\
\hline & Female & 192 & 34.7604 & 8.30410 & & \\
\hline \multirow{2}{*}{ Factor 2} & Male & 161 & 29.8137 & 5.32002 & \multirow{2}{*}{$-.1 .562$} & \multirow{2}{*}{.119} \\
\hline & Female & 192 & 30,6875 & 5.16191 & & \\
\hline \multirow{2}{*}{ Factor 3} & Male & 161 & 25,7267 & 5,25118 & \multirow{2}{*}{-.278} & \multirow{2}{*}{.782} \\
\hline & Female & 192 & 25.8750 & 4,77943 & & \\
\hline
\end{tabular}

As is seen in Table 2, the teacher candidates' epistemological beliefs significantly differed based on the major variable in all factors, [Factor 1 (F4-348=4.302, p<.05); Factor 2 (F4-348=3.857, p<.05); Factor 3 (F4-348=5.594, p<.05)]. The significant different in the sub-dimension related to the belief of learning depending on effort (Factor 1) was found to be in favor of the teacher candidates studying in the S.T. and S.S.T. programs. In the sub-dimension related to the belief of learning depending on talent (Factor 2), the significant difference was shown to be in favor of those studying in the E.T. program. As for the sub-dimension related to the belief of the existence of only one truth (Factor 3), the significant difference was in favor of those in the S.S.T., E.T., and P.T. programs.

Based on the findings revealed, it can be argued that S.T. and S.S.T. teacher candidates more strongly believed that learning depends on the effort compared to E.T. teacher candidates. Regarding the belief of learning depending on talent, S.S.T. teacher candidates had more developed/mature beliefs compared to other majors. Furthermore, related to the belief of the existence of only one truth, E.T., S.S.T. and P.T. teacher candidates were found to have more developed beliefs compared to S.T. teacher candidates. This result shows that the teacher candidates in the S.T. program more strongly believed the existence of only one truth compared to E.T., S.S.T. and P.T. teacher candidates.

Table 2. One-Way ANOVA Results of Teacher Candidates' Scores of Epistemological Beliefs Based on Major Variable

\begin{tabular}{lllllll}
\hline Variable & Major & $\mathrm{n}$ & $\boldsymbol{X}$ & $\mathrm{sd}$ & $\mathrm{F}$ & $\mathrm{p}$ \\
\hline & E.T. & 84 & 36,29 & 10,94 & 4302 & .002 \\
Factor 1 & S.T. & 68 & 32,01 & 7,14 & & \\
& E.M.T. & 89 & 35,92 & 8,27 & & \\
& S.S.T. & 58 & 33,08 & 6,69 & Major LSD test & \\
& P.T. & 54 & 37,46 & 10,28 & E.T.-S.T. & .004 \\
Factor 2 & Total & 353 & 35,02 & 9,06 & E.T.-S.S.T. & \\
& E.T. & 84 & 29,48 & 5,58 & 3857 & \\
& S.T. & 68 & 30,39 & 6,02 & & \\
& E.M.T. & 89 & 29,68 & 4,10 & & \\
S.S.T. & 58 & 32,62 & 4,14 & Major LSD test & \\
& P.T. & 54 & 29,88 & 5,80 & S.S.T.-All majors & \\
& Total & 353 & 30,28 & 5,24 & & \\
& E.T. & 84 & 25,53 & 4,78 & 5.594 & .000 \\
& S.T. & 68 & 27,60 & 5,42 & Major LSD test & \\
& E.M.T. & 89 & 26,48 & 4,35 & S.T.-E.T. & \\
& S.S.T. & 58 & 23,82 & 4,98 & S.T.-S.S.T. & \\
\hline
\end{tabular}


The results of Pearson Product-Moment Correlation Analysis conducted to examine the relationship between epistemological beliefs and grade point average are given in Table 3.

Positive significant relationship was determined between the teacher candidates' grade point averages and only the sub-dimension of the "belief of learning depending on talent" [ $\mathrm{r}=.114]$ among the factors of the epistemological beliefs scale. However, there were no significant relationships regarding the sub-dimensions of the beliefs of learning depending on effort [r=.-031] and the existence of only one truth [r=.001]. The scores obtained from the sample showed that among the epistemological beliefs, the belief related to talent was related to academic achievement.

Table 3. Correlation Matrix Between Teacher Candidates' Epistemological Beliefs and Grade Point Averages

\begin{tabular}{lllll}
\hline \multicolumn{1}{c}{ Variables } & 1 & 2 & 3 & 4 \\
\hline 1-Factor 1 & - & & & \\
2-Factor 2 & $-.207 *$ & - & & \\
3-Factor 3 & -.052 & $-.420 *$ & - & - \\
4-Grade Point Average & -.031 & $.114 *$ & .001 & \\
$\eta=353, * \mathrm{p}<.05$ & & & & \\
\hline
\end{tabular}

\section{Discussion}

In different studies examining epistemological beliefs, it is possible to find different results. For example, female and male elementary teacher candidates were shown to obtain different mean scores from the sub-dimensions related to epistemological beliefs. In this sense, while the female and male teacher candidates had different mean scores in Factor 1 "belief of learning depending on effort" and Factor 2 "belief of learning depending on talent", they had close mean scores in Factor 3 "belief of the existence of only one truth". The male teacher candidates had higher mean scores in Factor 1 "belief of learning depending on effort" and Factor 2 "belief of learning depending on talent" than the female teacher candidates. According to the t-test analysis conducted to identify whether the difference in the female and male elementary teacher candidates' mean scores in the sub-dimensions of epistemological beliefs were statistically significant, significant differences were revealed between the female and male elementary teacher candidates' mean scores in Factor 1 "belief of learning depending on effort" and Factor 2 "belief of learning depending on talent". However, there was no significant difference between the female and male elementary teacher candidates' mean scores in Factor 3 "belief of the existence of only one truth". As a result, it was found that the female elementary teacher candidates' epistemological beliefs in Factor 1 "belief of learning depending on effort" and Factor 2 "belief of learning depending on talent" were more developed/mature than those of the male teacher candidates, and their epistemological beliefs in Factor 3 "belief of the existence of only one truth" had similar characteristics. (Belet et al., 2011) In Belet and Güven's study titled "Examining Elementary Teacher Candidates' Epistemological Beliefs and Metacognitive Strategies", it is pointed out that there are various studies showing no relationship between elementary teacher candidates' academic achievement and epistemological beliefs, but they also indicated that Schommer (1993), Qian and Alvermann (2000), Deryakulu (2002), Schommer (1990), Ryan (1984), Schommer, Crouse and Rhodes (1992) showed that students with developed epistemological beliefs have high level of academic achievement. They stated that this discrepancy could be related to "sampling method" or "academic achievement scores obtained through a survey", and emphasized that this result is important in terms of making such studies more widespread (Belet et al, 2011).

While it is emphasized that the elementary teacher candidates' epistemological beliefs differed in favour of the females $(\mathrm{t}=1,74 \mathrm{p}<0,05)$, in other words the female teacher candidates' epistemological beliefs were more developed than the males, it was indicated that the answers given to the "Two-Factor Working Process Scale" did not reveal a significant difference, and thus, the female and male teacher candidates had similar learning approaches (Taşkın 2012).

In Tümkaya's (2012) study titled "Examining University Students' Epistemological Beliefs Based on Gender, Year of Study, Major, Academic Achievement and Learning Styles", there were not significant difference in the dependent variables based on gender and year of study (Wilk's Lambda $(\Lambda)=0.992 ; F(3,478)=1.221, p>.05$ ). This result showed that the values obtained for "belief of learning depending on effort" $(F(1,480)=1.259, \mathrm{p}>0.05)$, "belief of learning depending on talent" $(F(1,480)=1.087, p>0.05)$, "belief of the existence of only one truth" $(F(1,480)=0.885, p>0.05)$ were not statistically significant differences (Tümkaya, 2012).

However, in her study with high school students, Schommer (1993) found that epistemological beliefs was a determiner of general academic achievement, and grade level and intelligence was a determiner of epistemological beliefs. On the other hand, some studies revealed a significant difference in the sub-dimensions of "belief of learning depending on effort" and "belief of learning depending on talent" in favor of female students based on the gender variable, but in the sub-dimension of "belief of the existence of only one truth" did not show a significant difference. It was determined that female students more strongly believed in learning depending on talent rather than effort compared to male students. The results being different based on the gender variable may show that students' epistemological beliefs are shaped depending on the difficulties they encounter and the opportunities they have regarding the effort they make to gain more 
knowledge (Tümkaya, 2012).

According to another study, Arslan et al. found that the teacher candidates' learning strategies were a significant predictor of both female and male teacher candidates' beliefs of learning depending on effort (BLDE). While application strategy was the best predictor of male teacher candidates' BLDE, it was memory strategy for female teacher candidates. As application, memory and analysis strategies explained 99\% of male teacher candidates' BLDE, they explained $91 \%$ of female candidates' BLDE (Arslan et al., 2012).

According to the Mann-Whitney $U$ analysis based on the gender variable, there was no significant difference at the level of 0.05 for the answers given in the BLDE sub-dimension ( $U=4.3 ; p=0.87 ; p>0.05)$. As is seen in Table 3 , the female and male teacher candidates' mean ranks in BLDE were close to each other, and as a result, they were not different in terms of their tendency for BLDE.

A significant difference was revealed at the level of 0.05 for the answers given in the sub-dimension of belief of learning depending on talent (BLDT) based on the gender variable ( $U=3.6 ; p=0,048 ; p<0.05)$. Examining Table 4 to identify which group was in favor of this difference, it was seen that the female teacher candidates' mean ranks $(\mathrm{Sf}=95)$ was lower than the male teacher candidates' $(\mathrm{Sf}=112)$. It can be argued that as the scores obtained from the scale decreased, the beliefs would be more matured, and thus in this dimension, the female candidates was more developed. The results of the independent samples t-test showed no statistically significant difference at the level of 0.05 between teacher candidates' gender and the sub-dimension related to the belief of the existence of only one truth, $(\mathrm{t}=-0.89$; $\mathrm{p}=0.38 ; \mathrm{p}>0.05$ ) (Köse at al., 2012).

In the current study, the relationship between the teacher candidates' epistemological beliefs and academic achievement was examined. The results showed that there was a relationship between the sub-dimensions of epistemological beliefs (i.e. belief of learning depending on effort, belief of learning depending on talent and belief of the existence of only one truth) and academic achievement, which are discussed below.

According to the t-test results based on the gender variable, no significant differences were revealed for the teacher candidates' scores in Epistemological Beliefs Scale, including each of the three factors. It was found that the teacher candidates being male or female did not cause any difference in their belief of learning depending on effort (Factor 1), belief of learning depending on talent (Factor 2) and belief of the existence of only one truth (Factor 3). This result is also consistent with the studies in the literature.

According to the t-test results in terms of the gender variable, it was determined that the teacher candidates being male or female did not cause any difference in their belief of learning depending on effort (Factor 1), belief of learning depending on talent (Factor 2) and belief of the existence of only one truth (Factor 3) (see Table 1). When Table 2 is examined for the findings related to the teacher candidates' epistemological beliefs, their beliefs significantly differed based on the major variable in all factors, [Factor 1 (F4-348=4.302, p<.05); Factor 2 (F4-348=3.857, p<.05); Factor 3 (F4-348=5.594, $\mathrm{p}<.05)]$.

The significant different in the sub-dimension related to the belief of learning depending on effort (Factor 1) was found to be in favor of the teacher candidates studying in the S.T. and S.S.T. programs. In the sub-dimension related to the belief of learning depending on talent (Factor 2), the significant difference was shown to be in favor of those studying in the E.T. program. As for the sub-dimension related to the belief of the existence of only one truth (Factor 3), the significant difference was in favor of those in the S.S.T., E.T., and P.T. programs.

Positive significant relationship was determined between the teacher candidates' grade point averages and only the sub-dimension of the "belief of learning depending on talent" [ $\mathrm{r}=.114]$ among the factors of the epistemological beliefs scale. However, there were no significant relationships regarding the sub-dimensions of the beliefs of learning depending on effort [r=.-031] and the existence of only one truth [r=.001]. The scores obtained from the sample showed that among the epistemological beliefs, the belief related to talent was related to academic achievement.

\section{References}

Arslan, A., \&Fatime, U., \& Sadettin, Ş. (2012). The Predictive Power of the Teacher Candidates' Learning Strategies Related to Their Belief of Learning Depending on Effort. Mustafa Kemal University, and Institute of Social Sciences Journal, 9(19), 377-386.

Belet, Ş. D., \& Güven, M. (2011). Examining elementary teacher candidates' epistemological beliefs and metacognitive strategies. Educational Sciences: Theory \&Practice, 11(1), Winter, 31-57, Educational Counselling and Research Limited.

Bendixen, L. D. (2002). A process model of epidemic belief change. B. K. Hofer \& P. R. Pintrich (Ed.), Personel epistemology: The Psychology Of Beliefs About Knowledge And Knowing, Hillsdale, NJ: Erlbaum, 191-208. 
Brownlee, J. (2001). Epistemological beliefs in pre-service teacher education students. Higher Education Research and Development, 20(3), 281-291. http://dx.doi.org/10.1080/07294360120108377

Brownlee, J., Purdie, N., \& Boluton-Lewis, G. (2001). Changing Epistemological Beliefs in Pre-Service Teacher Education Students. Teaching in Higher Education, 6(2), 247-268. http://dx.doi.org/10.1080/13562510120045221

Çiğdem Ş. T. (2012). Epistemological Beliefs: A Variable Predicting Teacher Candidates' Learning Apparoaches, Mustafa Kemal University. Institute of Social Sciences Journal, 9(19), 273-285.

Deryakulu. (2004). The Relationship between university students strategies of learning and studying and their epistemological beliefs. Educational Administration: Theory and Practice, 38(55), 230-249.

Hofer, B. K., \& Pintrich, P. (1997). The development of epistemological theories: Beliefs about knowledge and knowing and their relation to learning. Review of Educational Research, 67, 88-140. http://dx.doi.org/10.3102/00346543067001088

İlhan, M., \& Çetin, B. (2013). Epistemological belief scale: validity and reliability study. Journal of Theoretical Educational Science, 6(3), 359-388. http://dx.doi.org/10.5578/keg.5952

Karasar, N. (2005). Scientific research methods, 14. edition, Ankara: nobel publishing.

Köse, S., \& Dinç, S. (2012). The relationship between science and technology teachers' biology self-efficacy perceptions and epistemological beliefs, Mustafa Kemal University. Institute of Social Sciences Journal, 9(18), 121-141.

Schommer, M. (1990). Effects of beliefs about the nature of knowledge on comprehension. Journal of Educational Psychology, 82(3), 498-504. http://dx.doi.org/10.1037/0022-0663.82.3.498

Schommer, M. (1993). Epistemological development and academic performance among secondary students. Journal of Educational Psychology, 85, 1-6. http://dx.doi.org/10.1037/0022-0663.85.3.406

Schommer, M. (1997). The development of epistemological beliefs among secondary students: A longitudinal study. Journal of Educational Psychology, 89, 37-40. http://dx.doi.org/10.1037/0022-0663.89.1.37

Schommer, M., \& Walker, K. (1995). Are epistemological beliefs similar across domains? Journal of Educational Psychology, 87, 424-432. http://dx.doi.org/10.1037/0022-0663.87.3.424

Schraw, G. (1998). Promoting general metacognitive awareness. Instructional Science, 26(1-2), 113-125. http://dx.doi.org/10.1023/A:1003044231033

Tümkaya, S. (2012). Examining University Students' Epistemological Beliefs Based on Gender, Year of Study, Major, Academic Achievement and learning styles. Educational Sciences: Theory \& practice, 1(12), 75-95, Educational Counselling and Research Limited,

Veenman, M. V. J., \& Hout-Wolters, Bernadette, H. A. M., \& Afflerback, P. (2006). Metacognition and learning: Conceptual and methodoligical considerations. Metacognition and Learning, 7, 187-209. http://dx.doi.org/10.1007/s11409-006-6893-0

\section{$(\mathrm{oc}) \mathrm{BY}$}

This work is licensed under a Creative Commons Attribution 3.0 License. 